\title{
Sobre poesia e rap, rappers e poetas
}

\author{
EMERSON DA CRUZ INÁCIO \\ Universidade de São Paulo
}

RESUMO: DISCUTIMOS NESTE ARTIGO A APROXIMAÇÃO ENTRE POESIA E OUTRAS MANIFESTAÇÕES POÉTICAS MAIS ATUAIS COMO O RAP, PROBLEMATIZANDO-A A PARTIR DE ESPAÇOS CARACTERIZADORES DA POESIA EM LÍNGUA PORTUGUESA, COMO A IDÉIA DE NACIONALIDADE, E RELACIONANDO TAIS FATORES AO PAPEL DA POESIA NA CONTEMPORANEIDADE.

ABSTRATC: WE DISCUSS IN THIS ARTICLE RAPPROCHEMENT BETWEEN POETRY AND OTHER CURRENT POETIC EXPRESSIONS, AS THE RAP, EXPLORING THE SPACES FROM THE CHARACTERISTIC OF POETRY IN PORTUGUESE, LIKE THE IDEA OF NATIONALITY, AND RELATING THESE FACTORS TO THE ROLE OF POETRY IN CONTEMPORARY SOCIETY.

PALAVRAS-CHAVE: POESIA - RAP - NACIONALIDADE KEYWORDS: POETRY - RAP - NATIONALITY 
onsiderando o crescente interesse pela relação Poesia, Crítica Literária e novas expressões da Cultura, queremos aqui sugerir a articulação entre o discurso próprio do poético - Literário, portanto - e o da Cultura de Massa, procurando entendê-los na sua dimensão dialógica e, quiçá, colaborativa. Entendemos aqui que é possível ser explicitada a relação entre aqueles discursos que, fundamentados na lógica cultural hegemônica, estão sempre funcionando como paradigmas em torno do qual gravitam a Literatura, por exemplo, e outros que, problematizando este paradigma, acabam por interferir na forma como o vemos.

Particularmente, quando nos deparamos com novos fenômenos da linguagem literária, produtos das sociedades capitalistas e da globalização cultural, nos deparamos também com o clássico enfretamento entre o que é e o que não é considerado literatura. Claro está que tal discussão advém do processo de institucionalização do discurso literário, decorrente da sua sedimentação como área específica do saber e como juízo estético particular sobre a linguagem. Esta afirmação específica da Literatura como uma disciplina instituise sobre um Cânone de prescrições e sobre uma História Literária que se demonstra, hoje, cada vez mais como um processo de escolhas ideológicas e de exclusões, que se baseia na recusa, na obliteração ou no escamoteamento de fenômenos estético-literários que correm em paralelo ao que a crítica canoniza e que transgridem a lógica estética requerida. A História da Literatura como a conhecemos, decorrência desse processo de institucionalização, tornar-se-á uma abordagem que recusa a própria Literatura, desconsiderando o jogo constante entre continuidade e descontinuidade que é própria da produção artística, já que aquela sacraliza justamente o caráter documental do texto literário, esvaziando-o de sua "lógica-monumento".

Pensando justamente que esse poder do literário como paradigma tem sido constantemente relativizado, gostaríamos aqui de apresentar algumas considerações sobre um fenômeno poético recente e próprio das culturas urbanas, que vem se constituindo como um outro dizer, para além do campo institucionalizado da poesia, o rap, partindo das possíveis relações de semelhança e articulação com o discurso poético sedimentado. 


\section{Estar à margem, mas dentro da poesia}

No Livro X da República, Platão propõe a expulsão do poeta da Cidade, já que este - seguidor de Homero, criador de mitos - não contribuía em nada para a formação do estado, nem para o seu louvor e nem para a formação do cidadão. Mas pelo contrário, a poesia traria à cidade e aos seus cidadãos o alimento das paixões, do prazer e dos sonhos, prejudiciais à construção da lei e da razão. Tal questão possibilita-nos pensar, hoje, a respeito do estatuto do poeta enquanto efetivo elemento de reflexão da vida, da sociedade e das questões engendradas atualmente em termos de necessidades políticas e sociais e, na esteira desse pensamento, na condição do poeta frente ao mundo em que se insere. Pode parecer, no pouco que aqui se disse, que pretendemos pensar qual o papel da poesia na modernidade, mas, antes, queremos refletir sobre o seu papel de objeto cultural efetivo, ao lado de outras manifestações literárias e culturais que residem ou na margem do cânone ou que ocupam um lugar fronteiriço, tanto em termos de inserção na mídia de massa e literária, quanto no que tange a sua recepção, aceitação e consagração em termos de crítica especializada.

Assim, nosso exercício reside no fato de que a poesia ocupa hoje, como no tempo de Platão, o exterior dos processos discursivos institucionalizados, como também - por pior que seja corromper ou estabelecer o mito - sequer é vista como manifestação capaz de proporcionar algum tipo de (in) formação ao indivíduo. Daí que podemos inferir que na atualidade a poesia e outras manifestações literárias ou dela derivadas não se encaixariam dentro de um projeto cultural ou mesmo de cidadania imaginados pelas políticas e modelos culturais hegemônicos globalizados dos Governos em geral.

Neste sentido, a modernidade fez do discurso poético não mais campo gerador da cultura, mas campo periférico, dependente de outras esferas da própria literatura, independentemente do crescente interesse e do crescimento das manifestações poéticas via blogs, publicações independentes e espaços dedicados a sua difusão. Não é demais pensarmos no fato de que no mercado editorial comercial, a presença de materiais que comentam ou se destinam ao entendimento do poético, sejam sensivelmente inferiores aos destinados à prosa. Em contrapartida, as páginas de divulgação de novos poetas são infinitamente mais acessadas e apresentam conteúdo com qualidade superior ao encontrado em sítios dedicados a outros gêneros literários. Fora do mercado 
literário tradicional, a poesia - periférica por natureza - segue seu rumo para fora da polis do cânone "dito" ocidental, criado pela mídia e pela crítica literária tradicional. A exemplo disso, os cada vez mais comuns coletivos, saraus, cooperativas e grupos de leitura de poesia espalhados pelas principais capitais brasileiras. Cremos que tal questão é mais uma decorrência do conjunto de situações que favorecem a elitização de determinadas artes, elitização aqui aplicada no sentido de estratégia discursiva e semântica e não só referente a uma determinada formação do gosto estético. De fato não é a poesia o melhor exemplo da linearidade, da lógica ou de verdades passíveis de serem veiculadas no interior dos biscoitos da sorte da vida ou nos cartões de aniversário. Antes, porém, o que caracteriza o poético é justo a sua força imagética e semântica, resultado de um hermetismo lingüístico (que longe de ser defeito é qualidade), que muitas vezes nos levam a crer que a poesia tem, sem exageros, um caráter iniciático e destinado ao deleite de alguns, apenas. Ou, como diria Michel Foucault, sobre a Literatura, o poético é, por sua natureza e sentido, a própria imagem da transgressão da linguagem.

Abandonando as questões clássicas e aprofundando o tom "romântico", a poesia, no correr dos últimos anos, veio ocupando um outro lugar, não menos elitizado nos seus sentidos, mas notadamente afastado daquela noção que motivava Platão a sugerir a expulsão do poeta da cidade. Ainda que saibamos que Homero não versejou contra seus líderes e sua pátria, também não fez nada que diminuísse a "grandeza épica de um povo em formação", como nos diz Caetano Veloso no rap "Haiti". Em outras palavras, a poesia se reestabelece na lógica cultural na medida em que ao invés de reafirmar os valores da sociedade ou do estado, surge como forma de mostrar os anseios de novos sujeitos e de novos cidadãos, frente às novas realidades que os cercam.

A poesia, então, passa a constituir-se como canto paralelo à sociedade, uma vez que na medida em que o pensamento de vanguarda permitia a experimentação expressiva e semântica, a poesia foi tomando posição como forma de comentar, profeticamente, todas aquelas situações que faziam do ser, do sujeito, do cidadão e da sociedade entidades cada vez mais esvaziadas de sentido, dentro da lógica espetacular da sociedade capitalista, como nos indica Guy Debord. Devemos ressaltar que profético aqui é usado não só no sentido daquilo que está em devir, como também como voz de denúncia, de questionamento e de justiça. 
Refletindo isso está toda uma gama de poetas de Língua Portuguesa, que desde Camões pelo menos, se estabelecem como denunciadores da relação homem-mundo. Este aspecto perpassaria o Romantismo de Castro Alves, o mal-estar de Cesário Verde, o desconforto diário de Drummond e desembocaria na produção poética de antilhanos como Cesáire, africanos como Jorge Barbosa, Francisco Tenreiro, Agostinho Neto, José Craveirinha, dentre outros, que vão transformar o texto poético num grande mural em que se estampam as necessidades de todo um povo, muitas vezes mantido às margens da produção literária como leitores e como objetos textuais.

A palavra poética, desta forma e por estes poetas, será assumida no século XXI, sobretudo, por indivíduos que irão valer-se dela como forma de dar legitimidade a um discurso que inicialmente nasce sem força estética, mas que através das literatura, por exemplo, irá constituir-se como exercício das utopias literárias, políticas e sociais de sociedades e populações.

A poesia produzida em Língua Portuguesa, em particular o rap será justamente uma das manifestações capazes de dar voz aos discursos silenciados pela história e pela cultura já há muitos séculos. As semelhanças entre estes dois objetos culturais - poesia e rap - não se dão apenas no aspecto engajado ou de denúncia até aqui referidas, mas também pelo tipo de relação que vem mantendo com a cultura midiática (e literária) institucionalizada e com os discursos literários e culturais canônicos e hegemônicos.

Constitui-se o rap como uma poética da margem no sentido mais amplo que a idéia de periferia pode aqui assumir: está, como sugere Platão, fora da metrópole, fora dos muros daquilo que a Literatura considera como perpetuação de valores estéticos capazes de transcender ao tempo e à noção de arte. O rap coloca-se como canto paralelo a uma concepção de poesia em que o lirismo romântico ou o tom excessivamente subjetivista tornam-se tônica do poético. Essa expressão poética reterritorializa a própria idéia de margem, já que, estabelecido nas bordas da cultura dominante, provoca um questionamento acerca da relação centro-periferia. Afinal, quem é a margem? Aquilo que se coloca como voz do sem-fala ou aquilo que tende a refletir o gosto estético de alguns? Finalmente, no caso de uma poesia cujo alcance político e estético transcende ao limite da própria nacionalidade e revela em si não só um projeto, mas toda uma "sagrada esperança", como pensar em quem representaria a cultura da elite e a cultura da massa, o cânone e a margem? 
São essas as questões que perpassam o estatuto do rap em termos culturais e literários, uma vez que ele é uma forma de expor uma realidade cuja tônica é justamente o isolamento, a falta, o exílio e a carência.

O discurso engendrado por esta forma poética se constitui como relatos de uma experiência só visível no campo do poético. A palavra, nesse caso, assume sua dupla capacidade: por um lado, revela seu poder encantatório, já que se mostra como síntese do vivido e do experimentado; por outro lado, articula novos sonhos e novas esperanças. Ela é a munição capaz de ferir sem sangrar, mas deixando marcas e expondo feridas recobertas pelas metáforas cotidianas. A palavra para Mano Brown (Racionais MC's), MV Bill, , Nega Gizza, Da Weasel são a metáfora de uma poesia que se pretende afirmativa, no sentido em que prevê, revê e prescreve um modo de estar no mundo, que sempre indica não o ideal mas o real que se estabelece como pano de fundo e material poético.

\section{Para além do paradigma poético da nacionalidade}

As estéticas trazidas e inauguradas pelos movimentos modernistas de Língua Portuguesa trouxeram definitivamente o paradigma da nacionalidade para o espaço da poesia, seja na reconfiguração da portugalidade procedida em Orpheu, seja assumindo definitivamente a nossa "cara" e a nossa língua, no caso brasileiro; Nesse sentido, queremos pensar a apropriação promovida por artistas do rap, brasileiros e portugueses, daqueles discursos também considerados "formadores" de nossa identidade cultural: o senso de nacionalidade e de identidade nacional. Claro está que, por sua ordem discursiva, tais discursos são pelo rap sempre colocados em suspensão, justo porque não entendem a nacionalidade como um ponto do qual emana a identidade, mas, sim, operam no sentido inverso: da margem da cultura advém outras falas capazes de interferirem mesmo na idéia de identidade supostamente assentada no nosso imaginário, como o gênero, a classe social e a identidade étnica. Assim, partiremos de dois modelos correntes de nacionalidade, amplamente divulgados e utilizados nas Literaturas e nas culturas Portuguesa e Brasileira, procurando refletir sobre como as produções culturais mais contemporâneas e marginais, como os raps dos brasileiros Racionais e MC's e MV Bill e dos 
portugueses Da Weasel, se apropriam daquelas idéias, produzindo com isso uma nova leitura/revisão dos discursos da identidade nacional.

A noção de nacionalidade que comumente vemos circulando nas letras de rap giram sempre, no caso brasileiro, em torno da idéia de não pertencimento, de não inclusão no panorama geral da brasilidade. De certa forma, isto decorre das fortes marcas sócio-culturais que estão na base desse produto cultural: a periferia, a pobreza, a tensão étnico-racial, a marginalidade da própria condição, que se constituem marcas caracterizadoras do rap nacional.

No exemplo português, embora tenhamos também a presença destes fatores, há o acréscimo decorrente da auto-percepção do rap como poesia que resiste à forte tradição poética presente naquele país. Em ambos os casos, a identidade nacional - seja aquela construída no mito da democracia étnicoracial e no abrandamento das diferenças, seja a outra, tecida sobe os grandes paradigmas instituídos desde o século XII - parece estar em constante rasura, ou em constante processo, no sentido que tanto em Portugal quanto no Brasil reclamam a modificação da idéia de nacionalidade e a sua abertura às novas demandas sociais, culturais e políticas que permeiam a produção do rap.

Não é à toa, que, por exemplo, o grupo português Da Weasel, procure sempre dialogar com um universo poético em cuja base estão artistas que se debruçaram efetivamente sobre o "ser português". Assim, Pessoa e Camões, os paradigmas frontalmente inatacáveis a que alude Maria Gabriela Llansol, e as idéias do português como homem assinalado, guerreiro e desbravador, cumpridor dos desígnios divinos que amparam os destinos da nação, cohabitam com outra visão mais atual em que pesam a cultura da fronteira, a migração, a situação semi-periférica do país, a tentativa de se ancorar na modernidade e o não-reconhecimento das "armas e dos barões assinalados" como síntese de uma identidade. Tudo isso em confronto, ainda, com "o jardim de paz e prosperidade sobre o mar plantado", expressão recorrentemente utilizada nos anos salazaristas como propaganda do imaginário lugar idílico, pátria de homens do campo, da saudade do passado, da simplicidade da vida tradicional e da negação da modernidade como único caminho. Talvez a fala mais emblemática a esse respeito possa ser sintetizada na letra de rap composta por ocasião da campanha pela Euro Copa de 2004, momento em que a seleção portuguesa fizera uma percurso nunca antes navegado nos campos de futebol. Lá, como aqui, também vemos em momentos de Copa do 
Mundo e quejandos o repentino renascimento de um civismo e de um senso de nacionalidade que pareciam adormecidos, próprio das multidões.

Mas, como na sua natureza o rap é o lugar de problematizar, esse renascimento interno do nacionalismo é motivo também para uma autognose, agora diferente daquela aludida por Eduardo Lourenço em seu Labirinto da Saudade: não é mais o momento de pensar o próprio destino como ficção do possível, mas, sim, sintonizá-lo a uma realidade mais imediata em que não há mais lugar para o entendimento de si próprio como um mito literário. Parafraseando Lourenço, é tempo, sim, de repensar o "irrealismo prodigioso da imagem que os portugueses se fazem de si mesmos", visto que a História nacional vertida e revertida em ficção até o século XIX, deve agora indicar em seu fluxo a efetiva realização dos próprios anseios, mesmo que seja num campo de futebol. Nessa seqüência, "Queremos mais", o rap em questão, que se auto-intitula "Hino Não-Oficial", já no seu título corrobora a idéia de que há um canto paralelo em que os heróis não mais estão no mar e onde se enfatiza o retorno ao esplendor de Portugal por outros caminhos:

Sem coisas de mão no peito e ar pesado

2004, o campeonato vai mudar o nosso fado

do coitado, do conformado, do comido

Porque é que o pais se queixa do que podia ter sido?

(DA WEASEL, 2005)

Observemos que este "grito do Ipiranga em versão portuguesa", como diz o rap, é enfático em tanto subverter o senso comum (coitado, conformado, comido), quanto está consciente de que o "fado" português tem efetivamente naquela campanha o seu momento de mudança. Não mais o "é a hora", um momento que nunca chega, e nem o da "lira destemperada e da voz enrouquecida", mas um efetivo tempo de se assumir a soberania do próprio destino, muito claro no constante uso do "nós" discursivamente inclusivo em toda a letra do rap. Ali, não mais a desistência camoniana em cantar essa gente surda e endurecida, mas de instá-la a assumir o seu poder de multidão frente ao que o senso comum da nacionalidade acreditava ser apenas um dever do estado. De certa maneira, a performance percebida na letra do rap tende a conclamar o português a assumir não a ficção do eterno porvir, mas, sim, em 
lugar disso, levá-lo a perceber que, como diz Boaventura de Souza Santos, "Portugal não tem destino. Tem passado, tem presente e tem futuro."

MV Bill e os Racionais MC's, rappers brasileiros, por sua vez e na falta de uma motivação cívica maior, tenderão a circunscrever uma identidade nacional no âmbito do que tradicionalmente não é tido como constituinte da brasilidade, mas que corre em paralelo a ela. Como já aludimos aqui, a consciência de sua própria situação de exclusão frente à cultura, à Literatura e à própria cidadania, tendem a produzir um discurso em que a tradicional visão do brasileiro produzida em José Alencar, no século XIX, e depois claramente criticada em Macunaíma, é substituída por uma lógica negativa em que não constam natureza, malandragem, ufanismo, identidade nacional conformada e onde também a idéia de que o Brasil, um país de todos, inexiste. Pretos, pobres, ex-detentos, marginalizados, moradores de favela, politicamente silenciados, contra os mitos da suposta igualdade racial e de condições, contra a virgem dos lábios de mel e o herói sem nenhum caráter! Se não nega tudo isso, pelo menos, assume-se como proposição em paralelo ao que comumente se apresenta como o senso comum de nossa brasilidade.

Quanto a isso, a voz de MV Bill nos parece tutelar: "A voz do excluído tá no ar / Mais um guerreiro do Rio de Janeiro / Buscando alternativa pra sair do coma brasileiro" (MV BILL, 2002). E este coma não só é o da própria letargia física a que este enunciador se encontra, mas de seu estado de ausência das condições de cidadania, que o constituiriam brasileiro. Nesse caso, o hino Nacional brasileiro parece ecoar ao fundo, já que este "mais um guerreiro", "filho teu que não foge à luta" deve necessariamente engendrar o combate pelo acesso coletivo aos bens morais que podem efetivamente torná-lo brasileiro.

"Ser um preto tipo A custa caro", como afirmam os Racionais MC's (1997). Como custa caro também ser brasileiro e em torno de ser negro constituir em paralelo a sua nacionalidade. Claro está que o jogo entre etnia e identidade nacional revela também não só os jogos de exclusão, mas mais ainda toda a estranha relação da cultura brasileira com a sua matriz africana, uma vez que ao mesmo tempo em que esta parece estar no cerne da nossa formação identitária, parece ao mesmo tempo em vários graus diluída, hibridizada, mesclada e mestiçada com outros aspectos das demais culturas formadoras.

Ao lado de expressões e de uma cadeia semântica e vocabular própria da periferia, como o "guerreiro", de MV Bill, e o "preto tipo A", dos Racionais, 
há o constante resgate daquelas figuras que, desbaratadas da brasilidade essencial, vão constituir uma nacionalidade em paralelo ou ao menos demarcar que o ser brasileiro nasce em Zumbi, Ganga Zumba e nos navios negreiros. Ser brasileiro é ser preto tipo A, para o rap; é uma recusa da malandragem, dos esteriótipos colocados ao morador da periferia e ao não-lugar a ele destinado no momento solar da formação da nossa nacionalidade. São os mitos-heróis da brasilidade, mas produtos fora do campo em que ela tradicionalmente se constituiu. Nesse sentido, quando Mano Brown, voz dos Racionais, enuncia o negro e aquela realidade a que está submetido com constância, também parece afirmar que há ali um viés da nossa identidade que se oblitera frente às formas mais hegemônicas daquilo que pensamos como nossa identidade.

Noutras palavras, ao negar e rever a formulação assentada de nacionalidade, o rap introduz nesse campo outros elementos que sintonizam essa mesma identidade nacional no campo das novas políticas culturais, próprias de tempos em que os atores sociais em emergência -minorias culturais, exilados, identidades não-normativas - passam a reclamar seu estatuto no campo cultural, estético, literário e político, seja no Brasil, seja em Portugal. Se a poesia produzida nesses dois espaços caracterizou, na história mais recente, também a sua nacionalidade, não é forçoso pensar que, diante das novas demandas, o rap venha a representar uma forma outra de conceber e definir essa identidade nacional, frente aos desafios cada vez maiores da globalização, da cooptação da política da diferença pelo mercado e da suposta equiparação cultural sugerida por conceitos como hibridização e mestiçagem.

No contexto da globalização dos bens culturais, movida pela indústria cultural, o conceito de cultura local/ nacional se encontra atualmente em suspenso. Essa suspensão se dá pelo fato de que as fronteiras culturais que delimitavam as trocas simbólicas nacionais estarem em franca desarticulação. Dessa maneira, rever políticas culturais torna-se uma urgência, não só pela defesa da memória e de novas identidades nacionais, mas para se perceber o valor simbólico que a nacionalidade assume diante do processo das trocas culturais. Nessa esteira, rever o cânone literário, sua constituição e o manejo que estes dispensam a certos fenômenos da cultura local, também se torna necessário, principalmente em tempos que o estatuto da Literatura, do Literário e dos sistemas de representação que os suportam também denotam sua crise. 


\section{Referências Bibliográficas}

DA WEASEL. Re-Definições [CD]. Portugal: EMI, 2005 [Edição Especial]

RACIONAIS MC’s. Sobrevivendo no Inferno. Brasil: Zâmbia Fonográfica, 1997.

MV BILL. Declaração de guerra. Brasil: Natasha Records/BMG, 2002. 